\title{
Drug for Further Processing
}

National Cancer Institute

\section{Source}

National Cancer Institute. Drug for Further Processing. NCI Thesaurus. Code 194795.

A drug (other than the bulk ing redient API) that is in an interim stage of manufacture, processing, preparation, or packaging, and not ready for human or animal use. 